\title{
O INVENTÁRIO DO ACERVO PARCIAL DO SISTEMA INTEGRADO DE BIBLIOTECAS DA BIBLIOTECA UNIVERSITÁRIA DA UNIVERSIDADE REGIONAL DE BLUMENAU (FURB): RELATO DE EXPERIÊNCIA
}

\section{Evanilde Maria Moser \\ Jane Cristina Casas \\ Maria Genoveva Lemos}

\section{Resumo:}

Relato de experiência do inventário parcial do acervo do Sistema Integrado de Bibliotecas da Biblioteca Universitária da Universidade Regional de Blumenau realizado nas Bibliotecas do Campus I, III e IV com o objetivo de descrever a metodologia adotada nas unidades citadas. Os resultados indicam alguns problemas $0,33 \%$ ao longo de 14 anos como erros de digitação de registro, de classificação, entre outros. Apontam também um extravio de aproximadamente $0,11 \%$ ao ano no Campus I, 0,009\% no Campus III e IV. Concluiu-se que, apesar do extravio e problemas detectados serem pouco significativos em relação ao acervo analisado, pode-se fazer um estudo com mais detalhes para melhorar cada vez mais este índice.

\section{Palavras-chave:}

Universidade regional de Blumenau; Biblioteca universitária; Bibliotecas universitárias - inventários; Materiais bibliográficos - inventários

\section{INVENTORY OF THE PARTIAL COLLECTION OF THE UNIVERSIDADE REGIONAL DE BLUMENAU (FURB)'S INTEGRATED LIBRARY SYSTEM: EXPERIENCE REPORT}

\begin{abstract}
:
This is an experience report about the partial inventory of the collection of Universidade Regional de Blumenau's Integrated Library System made at campi I, III and IV Branch Libraries, with the purpose of describing the methodology adopted by each one. Results over the last 14 years indicate some problems such as: $0.33 \%$ typing errors on number registration, material classification, among others. Results also demonstrate an annual rate of about $0.11 \%$ per year for lost materials at Campus I, and $0.009 \%$ at Campi III and IV. The conclusion is that, despite lost materials and detected problems being less significative in relation to the analized collection, a detailed study can be made to improve these rates.
\end{abstract}

\section{Keywords:}

Regional University of Blumenau; University library; University libraries - inventory; Bibliographic materials - inventories. 


\section{INTRODUÇÃO}

Nas universidades as bibliotecas têm um importante papel, são os locais onde a informação - instrumento essencial ao ensino, pesquisa e extensão - é selecionada, processada, organizada, disponibilizada e disseminada. “Através dos séculos, o ponto focal da universidade tem sido a biblioteca, com o seu acervo de obras impressas preservando o conhecimento da civilização.” (CUNHA, 2000, p. 71).

Para que a biblioteca cumpra a sua missão de disponibilizar a informação aos seus usuários é imprescindível manter o acervo organizado, de maneira que as informações sobre os itens constantes no catálogo sejam condizentes com o item e com a sua localização na Biblioteca.

Desta forma, o inventário do acervo é uma atividade que permite detectar as falhas e verificar quais itens não estão de acordo com a indicação do catálogo.

Na Biblioteca Universitária da Universidade Regional de Blumenau (BU/FURB) foi realizado, em janeiro de 2007 um inventário parcial do acervo bibliográfico. Apesar da literatura afirmar que o inventário deve ser efetuado periodicamente, a Biblioteca da FURB está fazendo o seu pela segunda vez. A primeira vez, ocorreu por ocasião da automação do empréstimo, em 1993.

O projeto de automação do empréstimo da Biblioteca, trouxe como fator primordial a exigência de inventariar o acervo bibliográfico. Com a implantação do código de barras nos volumes, foram gerados 110.000 códigos, entretanto, foram localizados aproximadamente 90.000 volumes.

O resultado deste primeiro inventário, realizado após 24 anos de funcionamento de Biblioteca, apresentou um extravio de aproximadamente 20.000 volumes (3,40\% por ano), ou seja, aproximadamente 833 volumes por ano. Levando-se em consideração o longo período sem realizar tal atividade, e que os mecanismos de controle de entrada e saída de usuários, na época, eram precários, ou seja, praticamente inexistia, o quantitativo realizado encontrava-se na média. 
O objetivo deste trabalho é relatar a experiência vivenciada pelos servidores da Biblioteca da FURB ao inventariar pela segunda vez algumas coleções como: Coleção Geral (CG), Especial (CE), Referência (RF), Monografias (MO), Teses e Dissertações (TE), Folhetos (FF), Obras Raras (OR), Relatórios de Pesquisa (RP), Mapas (MP), da Biblioteca Central do Campus I, bem como o acervo dos Campus III e IV do Sistema de Bibliotecas da Universidade Regional de Blumenau (FURB).

\section{CONTEXTUALIZAÇÃO DA BIBLIOTECA UNIVERSITÁRIA DA FURB}

A Universidade Regional de Blumenau é uma Instituição Pública municipal mantida pela Fundação Universidade Regional de Blumenau. Foi criada em dezembro de 1967, constituída pela Faculdade de Ciências Econômicas, Faculdade de Direito e Faculdade de Filosofia, Ciências e Letras. Posteriormente, em 1968, o então Diretor Geral, Professor Martinho Cardoso da Veiga fundou a Biblioteca Central - atual Biblioteca Universitária.

A Biblioteca Universitária mantém o Sistema Integrado de Bibliotecas que é formada por uma Biblioteca Central, e quatro Bibliotecas Setoriais, alocadas nos Campi da Instituição, atendendo 39 cursos de graduação, 37 cursos de pós-graduação em nível de especialização (sendo 27 na Sede e 10 fora da Sede) 7 em nível de mestrado, além de 3 cursos seqüenciais e uma escola de Segundo Grau - ETEVI, possuindo um acervo de 481.909 volumes (incluindo-se materiais especiais, periódicos e multimeios).

O quadro de pessoal da Biblioteca Universitária é constituído por 15 bibliotecários, 01 analista de sistemas, 02 auxiliares em assuntos de informática, 01 técnico em arquivo, 04 assistentes administrativos, 09 auxiliares administrativos, 16 auxiliares de biblioteca, 02 encadernadores, 03 assistentes operacionais, 38 bolsistas e 02 estagiários da Secretaria Estadual da Educação.

Em 1996 foi instalada a Biblioteca Setorial do Campus II, para atender a comunidade acadêmica dos cursos de Engenharia Industrial Elétrica, Engenharia Química e Educação Artística, além do corpo técnico-administrativo do Instituto de Pesquisas Tecnológicas (IPTB).

Foi a partir de março de 2000 que entraram em funcionamento: a Biblioteca Setorial do Campus III, para atender os cursos de Odontologia e de Farmácia e a Biblioteca Setorial 
de Gaspar, para atender, inicialmente, o curso de Pedagogia e a partir de 2003 o curso de Administração.

Em 2002, iniciou-se as obras de ampliação do prédio da Biblioteca Universitária e a implantação da Biblioteca Setorial do Campus IV, instalada para atender alunos e professores dos cursos de Ciências da Computação e de Sistemas de Informação.

\section{REFERENCIAL TEÓRICO}

O acervo é a base de uma Biblioteca, através do qual são realizados os serviços meio e fim (MACIEL, 1995). Para manter a organização e o controle patrimonial do acervo é necessário realizar o inventário, que é um levantamento do material existente no acervo confrontando-se com o que foi registrado anteriormente. Segundo VanOrden ${ }^{1}$ (1982 apud BASINGER, 2005, p. 8),

Inventário é o processo pelo qual itens e informação listadas em fichas registradas são verificados, e a condição física de cada um é avaliado. O registro deve indicar o número de cópias correntes, a condição física do item e seu conteúdo, a circulação do registro (cartão e bolso), e a informação catalogada deveria ser checada.

Chiavenato (2005, p.133) conceitua inventário como “verificação de ou confirmação da existência de materiais ou bens patrimoniais da empresa.” Na visão de Peñasola (1961, p. 123), “o inventário é uma confrontação das coleções com as fichas que elas representam, ou sejam, as do catálogo topográfico.”

Para Pierotti e Neils (1985, p. 59),

o inventário é uma das atividades do serviço de referência, que possibilita o conhecimento adequado e a avaliação do estado da coleção da biblioteca. Por estas razões o inventário exige do bibliotecário uma grande carga de trabalho para cumprir etapas diversificadas, tais como cobertura, análise e avaliação do acervo.

No inventário tradicional para confrontar o catálogo topográfico ou os relatórios resultantes de catálogos automatizados com todos os itens dispostos nas estantes é preciso uma preparação prévia, desta maneira, deve-se colocar

todo o material em perfeita ordem, fazendo-se uma leitura minuciosa das estantes e do catálogo topográfico, que está ordenado pelo número de chamada, correspondente à ordem nas estantes. Para a execução propriamente dita os funcionários dividem-se em grupos de trabalho. Cada grupo inventariará um assunto (classificação) predeterminado. Faz-se conferência do material com o catálogo topográfico (PIEROTTI e NEILS, 1985, p. 60).

\footnotetext{
${ }^{1}$ VanOrden, P.J. The collection programs in elementary and middle schools: concepts, practices, and informa tion sources. Littleton, CO: Libraries Unlimited, 1982. p. 239-240.
} 
Pode-se, também, realizar o inventário rotativo, que “é projetado para ser continuamente atualizado. Assim, o acervo é controlado constantemente, permitindo que a quantidade total de itens a serem inventariados em um determinado período seja reduzido ao mínimo.” (PIEROTTI e NEILS, 1985, p. 61).

\section{METODOLOGIA DO INVENTÁRIO NA BIBLIOTECA UNIVERSITÁRIA}

No decorrer das atividades do ano de 2006, se decidiu realizar o inventário do acervo da BU/FURB. Em reunião, os bibliotecários estabeleceram que esta atividade fosse realizada sem que os serviços da biblioteca fossem interrompidos, pois "a paralisação do atendimento ao usuário é um fator de grande inibição e constrangimento, que pode causar o afastamento definitivo do leitor da Biblioteca.” (PIEROTTI e NEILS, 1985, p. 61).

A manutenção do controle patrimonial do acervo é competência da Seção de Processamento Técnico e Encadernação (FUNDAÇÃO UNIVERSIDADE REGIONAL DE BLUMENAU, 2006), entretanto, para a melhor operacionalização da atividade, o grupo de trabalho foi formado, principalmente, pelos funcionários e bolsistas da Seção de Serviços aos Usuários, e coordenado pela Bibliotecária Chefe desta Seção, cujo quadro de funcionários é maior e trabalha num horário mais amplo. Contando, também, com o apoio de funcionários das outras Seções e Bibliotecas Setoriais.

Para que pudesse ser efetuado no menor tempo e da melhor maneira possível, o inventário foi planejado em algumas etapas, o mesmo proposto no quadro 1, por Chiavenato (2005).

Quadro 1 - Etapas do inventário

\begin{tabular}{|l|l|}
\hline Proposta de Chiavenato (2005) & Proposta das Autoras \\
\hline Convocação das equipes & Equipe formada por duplas \\
\hline Arrumação física & $\begin{array}{l}\text { Os itens já se encontravam organizados } \\
\text { por ordem de classificação }\end{array}$ \\
\hline Cartão de inventário & $\begin{array}{l}\text { Listagem/relatório das obras por ordem } \\
\text { de classificação }\end{array}$ \\
\hline Atualização dos registros de estoque & $\begin{array}{l}\text { Registro das seguintes informações com } \\
\text { data: não localizado, catalogação } \\
\text { retrospectiva, descarte, e inventário }\end{array}$ \\
\hline
\end{tabular}




\begin{tabular}{|l|l|}
\hline Contagem de estoque & $\begin{array}{l}\text { Verificação dos itens na estante de } \\
\text { acordo com a listagem/relatório }\end{array}$ \\
\hline Reconciliação e ajuste & $\begin{array}{l}\text { Verificação dos itens não localizados } \\
\text { em outras coleções } \\
\text { Ajuste nas etiquetas do código de barras }\end{array}$ \\
\hline
\end{tabular}

Fonte: Adaptado de Chiavenato (2005, p.134-135)

\subsection{BIBLIOTECA CENTRAL}

O levantamento do acervo, realizou-se entre 08 e 31 de janeiro de 2007, na Biblioteca Central. Optou-se pelo inventário tradicional, sob a coordenação da Bibliotecária Chefe da Seção de Serviços ao Usuário, e consistiu em requerer uma listagem/relatório impressa(o) dos registros do acervo por ordem de classificação de cada Biblioteca para confrontação dos itens da listagem/relatório com as obras do acervo.

O inventário poderia ser realizado com um leitor de códigos de barras, o que seria mais rápido. Entretanto a escolha da listagem/relatório ocorreu, porque, ao inventariar o acervo conferindo-se os itens de acordo com a lista, seria possível a identificação de falhas que o equipamento não detectaria.

Em um primeiro momento, foram constituídas várias equipes, formadas por duplas, que eram destinadas às áreas de classificação distintas. Um integrante da dupla ditava o número de registro e outro conferia na listagem/relatório, assinalando os itens não localizados.

Em um segundo momento, outra dupla verificava a situação dos itens assinalados. Esta verificação foi feita no Catálogo on-line do acervo da Biblioteca, para saber se o item não localizado estava emprestado, sendo encadernado, aguardando para ser reposto (carrinho) ou em transferência para outra Biblioteca.

Caso o item, anteriormente não localizado, fosse encontrado, a lista era atualizada com uma nova informação. Se constasse no catálogo que a obra estava disponível e esta não fosse encontrada, assinalava-se o registro da obra na listagem/relatório com uma caneta destaque, ressaltando que a mesma não fora localizada. 
Depois disto, as listagens foram encaminhadas ao Coordenador que as organizava e redistribuía para uma segunda verificação nas outras coleções: Coleção Geral (CG), de Referência (RF), de Monografias (MO), de Teses e Dissertações (TE), de Folhetos (FF), de Obras Raras (OR), de Depósito (DT).

Encerrada a verificação nas coleções da Biblioteca Central, as listagens/relatórios foram encaminhadas (o) às Bibliotecas Setoriais, a fim de conferir se obras pertencentes ao acervo da Biblioteca Central não estavam armazenadas nestas Setoriais.

\section{CAMPUS III}

O levantamento do acervo realizou-se nos dias 05 de fevereiro (das 8:00 às 11:30) e 07 de fevereiro (das 09:00 às 11:00 e das 13:00 às 14:00), com a Biblioteca fechada, como é prática neste Campus, no período de férias. O levantamento do acervo contou 03 funcionários, com 02 máquinas coletoras de estatística SCANPAL 2C Datacollector. As máquinas foram passadas em cada código de barra para a leitura do registro da obra. E, quando, por algum motivo, a coletora não lia o código, era digitado o código correspondente.

Os dados coletados foram descarregados e analisados, verificando-se o que pertencia à Biblioteca do Campus III, fazendo-se uma confrontação com os dados levantados, possibilitando avaliar o que pertencia ao referido Campus e que não fora lido pela máquina, bem como, recuperar o que fora lido como desse acervo, e que não pertencia ao mesmo.

Optou-se por realizar o inventário com o leitor de código de barras, por ser um acervo pequeno, e por já ter sido inventariado anteriormente pela mesma metodologia.

\section{CAMPUS IV}

O levantamento do acervo realizou-se em 14 de fevereiro e finalizou-se em 23 de fevereiro de 2007. A metodologia utilizada foi a mesma descrita para a Biblioteca Central do Campus I, e contou com uma listagem/relatório impressa(o) dos registros por ordem de classificação do acervo do Campus IV. Foram envolvidos 03 funcionários. 
5 RESULTADOS DO INVENTÁRIO DA BIBLIOTECA UNIVERSITÁRIA

Os resultados do inventário realizado em 2007, indicam os problemas e extravios detectados ao longo dos últimos 14 anos, e podem ser observados nas Bibliotecas do Campus I, III e IV.

De acordo com Peñasola (1961, p.123) o inventário é uma oportunidade ímpar de se poder fazer correções "de uma forma sistemática e completa, já que todas as coleções da biblioteca estão sendo inspecionadas." E assinala ainda que "ao fazer a confrontação deve-se indicar toda a discrepância entre o fichário [catálogo on-line] e o material colocado nas estantes.”

\subsection{RESULTADOS DO INVENTÁRIO DA BIBLIOTECA CENTRAL (CAMPUS I)}

Os resultados do inventário indicam que os principais problemas detectados na Biblioteca

Central, como pode ser observados na tabela 1, foram:

a) erro na digitação do registro, da classificação, e nos dados descritos no catálogo on-line;

b) volumes de um tipo de coleção, mas guardados em outro tipo de coleção;

c) volumes que foram localizados, mas que estavam registrados como excluídos/não localizados;

d) volumes de Setorial, mas guardados na Biblioteca Central;

e) volumes com o mesmo registro em coleções e classificações diferentes;

f) volumes com o mesmo registro em coleções e classificações iguais;

g) constava como emprestado e estava na estante;

h) erro de encadernação - capa trocada.

Considera-se esses erros, num total de 681 insignificantes (0,33\%) levando-se em consideração o acervo total das coleções analisadas na Biblioteca Central (205.478 volumes).

Tabela 1 - Problemas detectados no decorrer do inventário na Biblioteca Central do Campus I 


\begin{tabular}{|c|c|}
\hline Problemas - Situação & Número de volumes \\
\hline Constava como emprestado e estava na estante & 05 \\
\hline $\begin{array}{l}\text { Volumes de um tipo de coleção, mas guardados em } \\
\text { outro tipo de coleção }\end{array}$ & 258 \\
\hline $\begin{array}{l}\text { Volumes que foram localizados, mas que estavam } \\
\text { registrados como Excluídos/não localizados }\end{array}$ & 99 \\
\hline $\begin{array}{l}\text { Volumes com o mesmo registro em coleções e } \\
\text { classificações diferentes }\end{array}$ & 16 \\
\hline $\begin{array}{l}\text { Volumes com o mesmo registro e mesma classificação } \\
\text { em coleções diferentes }\end{array}$ & 14 \\
\hline $\begin{array}{c}\text { Volumes com o mesmo registro em coleções e } \\
\text { classificações iguais }\end{array}$ & 06 \\
\hline $\begin{array}{l}\text { Erro na digitação do registro, da classificação, e nos } \\
\text { dados descritos no catálogo on-line }\end{array}$ & 264 \\
\hline $\begin{array}{l}\text { Volumes de Setorial, mas guardados na Biblioteca } \\
\text { Central }\end{array}$ & 17 \\
\hline Erro de encadernação - capa trocada & 02 \\
\hline Total de erros do acervo inventariado & 681 \\
\hline
\end{tabular}

Fonte: Dados do Inventário 2007

Como pode ser observado (tabela 2) na Biblioteca Central, de um total de 205.478 volumes do material analisado, 3.417 volumes não foram localizados, dando um percentual de perda de 1,66\%, ao longo de 14 anos, ou seja, aproximadamente uma média de $0,11 \%$ ao ano.

Withers² (1974 apud CARVALHO, 1981, p. 19) afirma que "padrões para bibliotecas são essenciais para o planejamento de serviços e conseqüentemente para sua avaliação”. Apesar da literatura associar o conceito de padrão aos de norma e diretriz quando se trata de medidas estabelecidas para avaliação e controle, ao mesmo tempo, não define o que é considerado um indicador para perdas/furtos/extravios do acervo em Bibliotecas.

A Associação Brasileira de Supermercados (ABAS) (2007) por sua vez, em estudo anual para verificar o quanto as perdas comprometem financeiramente as empresas varejistas brasileiras mostrou que, em 2005, a perda total do setor chegou a 2,05\%. Em 2004, o indicador foi de $1,78 \%$, e em 2003 , de $2 \%$.

${ }^{2}$ WITHERS, F. N. Standarts for library service: an international survey. Paris: UNESCO, 1974. 421p. 
Fazendo-se uma analogia com a ABAS, pode-se constatar que as perdas/extravios da Biblioteca Universitária da FURB estão aquém da média.

A tabela 2 revela que a Coleção Especial teve um extravio de aproximadamente 3,81\%, representando um alto índice, considerando-se às demais coleções, mas, levando-se em consideração os 14 anos sem inventário, pode-se considerar pouco significativo (cerca de $0,27 \%$ ao ano).

Para facilitar a análise dos resultados, a coleção de referência e a coleção geral, foram classificadas e subdivididas em pequenos grupos de assuntos de acordo com a Classificação Decimal de Dewey (CDD), sistema utilizado na Biblioteca Universitária. Desta forma, pode-se verificar melhor a área sobre a qual recai o maior número de perdas e rever algumas decisões. (Apêndice A e B)

Destaca-se, porém, que as divisões foram feitas considerando-se apenas duas casas decimais, entretanto, para uma melhor análise dos dados, utilizou-se três casas decimais, para o Campus III e IV.

Ressalta-se que as áreas mais prejudicadas na Coleção de Referência (CR), por ano foram: as áreas 800 com 0,43\%; seguida da 100 com 0,29\%, 400 com 0,27\%; 700 com 0,21\% , considerando-se as aquisições da área analisada, como podem ser observadas no Apêndice B.

Em relação à Coleção Geral (CG) destacam-se as áreas com maior extravio ao ano considerando-se as aquisições de cada área : 004 a 019 com 1,28\%; 028.5 a 029 com 0,59\%; 690 a 699 com 0,55\%; 520 com 0,53\%; 620 a 629 com 0,45\%; 820 a 829 com 0,30\%; 630 a 639 com 0,28\%; 100 a 149 com 0,25\%; 500 a 519 com 0,23\%; 810 a 819 com $0,21 \%$. Observa-se que as demais áreas com perdas inferiores podem ser conferidas no Apêndice B.

Tabela 2 - Volumes não localizados por tipo de Coleção na Biblioteca Central (Campus I)

\begin{tabular}{c|c|c|c|c}
\hline Tipo de coleção & $\begin{array}{c}\text { Total de volumes } \\
\text { no acervo }\end{array}$ & $\begin{array}{c}\text { Volumes não } \\
\text { localizados }\end{array}$ & $\begin{array}{c}\% \\
\text { Em 14 anos }\end{array}$ & $\begin{array}{c}\% \\
\text { anual }\end{array}$ \\
\hline
\end{tabular}




\begin{tabular}{c|c|c|c|c}
\hline $\begin{array}{c}\text { Coleção Especial } \\
\text { (CE) } \\
\text { Coleção de Obras } \\
\text { Raras (OR) }\end{array}$ & 2.358 & 90 & 3,81 & 0,27 \\
$\begin{array}{c}\text { Coleção de Folhetos } \\
\text { (FF) }\end{array}$ & 570 & $01^{*}$ & 0,17 & 0,01 \\
$\begin{array}{c}\text { Coleção de } \\
\text { Monografias (MO) } \\
\text { Coleção de Teses } \\
\text { (TE) }\end{array}$ & 5.129 & 46 & 0,65 & 0,04 \\
$\begin{array}{c}\text { Coleção de } \\
\text { Relatórios de }\end{array}$ & 126 & 06 & 0,58 & 0,04 \\
$\begin{array}{c}\text { Pesquisa (RP) } \\
\text { Coleção de Mapas } \\
\text { (MP) }\end{array}$ & 1.196 & - & 0,25 & 0,01 \\
$\begin{array}{c}\text { Coleção de } \\
\text { Referência (RF)** } \\
\text { Coleção Geral } \\
\text { (CG)*** }\end{array}$ & 177.037 & 21 & - & - \\
\hline Total & $\mathbf{2 0 5 . 4 7 8}$ & $\mathbf{3 . 4 1 7}$ & 1,75 & 0,12 \\
\hline
\end{tabular}

- $\quad$ *a Biblioteca possui um outro exemplar em duplicata

- $\quad$ ** informações mais detalhadas ver Apêndice A

- $\quad * * *$ informações mais detalhadas ver Apêndice B

Fonte: Dados do Inventário 2007

\subsection{RESULTADOS DO INVENTÁRIO DA BIBLIOTECA DO CAMPUS III}

A tabela 3 aponta um índice pouco expressivo de 0,009\% de material de extraviado ao ano, neste campus. E não foi detectado nenhum problema de digitação e /ou classificação.

Tabela 3 - Volumes não localizados no Campus III

\begin{tabular}{|c|c|c|c|c|}
\hline Classificação & Total de volumes & $\begin{array}{l}\text { Volumes não } \\
\text { localizados }\end{array}$ & $\begin{array}{c}\% \\
\text { Em } 14 \text { anos }\end{array}$ & $\begin{array}{c}\% \\
\text { anual }\end{array}$ \\
\hline Total & 4.381 & 06 & 0,13 & 0,009 \\
\hline
\end{tabular}

Fonte: Dados do Inventário 2007

\subsection{RESULTADOS DO INVENTÁRIO DA BIBLIOTECA DO CAMPUS IV}


A tabela 4 aponta um índice pouco significativo de 0,009\% de material extraviado ao ano, no campus. Entretanto, foram detectados: 08 volumes com erros de digitação, e 03 volumes que pertenciam à Biblioteca Central e estavam no Campus IV.

Tabela 4 - Volumes não localizados no Campus IV

\begin{tabular}{c|c|c|c|c}
\hline Classificação & Total de volumes & $\begin{array}{c}\text { Volumes não } \\
\text { localizados }\end{array}$ & $\begin{array}{c}\mathbf{\%} \\
\text { Em 14 anos }\end{array}$ & $\begin{array}{c}\mathbf{\%} \\
\text { anual }\end{array}$ \\
\hline 001.4 a 003 & 66 & - & - & - \\
004 a 006 & 6.211 & 09 & 0,14 & 0,010 \\
153 a 920 & 1.013 & 01 & 0,09 & 0,006 \\
\hline Total & $\mathbf{7 . 2 9 0}$ & $\mathbf{1 0}$ & $\mathbf{0 , 1 3}$ & $\mathbf{0 , 0 0 9}$ \\
\hline
\end{tabular}

Fonte: Dados do Inventário 2007

\section{CONCLUSÃO E RECOMENDAÇÕES FINAIS}

Pretende-se dar continuidade a este inventário, nas Coleção de Periódicos (CP) de todas as Bibliotecas. E, iniciar o inventário no Campus II e na Setorial de Gaspar a partir de Julho do corrente ano.

O inventário aponta baixas e perdas dos livros adquiridos pela Biblioteca ao longo dos últimos 14 anos, além de revelar aspectos qualitativos do acervo como o valor das obras, estado de conservação, possibilitando a correção dos problemas de reposição do material na estante, processamento técnico e identificação das áreas mais problemáticas, como pode ser observado na tabela 2. Indica ainda que, a Coleção Especial (CE) precisa de investimento na substituição do material extraviado, bem como um controle maior sobre esse acervo.

Uma alternativa seria rever se algumas obras da Coleção Especial (CE) poderiam ser consideradas como Coleção de Obras Raras (OR) como estabelece a Biblioteca Nacional, e guardá-la como tal, onde o acesso na Biblioteca Central é restrito, pois fica em uma sala separada.

acervo de obras raras é constituído de material bibliográfico diversificado - livros, folhetos, folhas volantes, periódicos - e selecionado segundo parâmetros que o consideram raro ou precioso. Segundo esses parâmetros, não basta ser antigo, é 
preciso ser único, inédito, fazer parte de alguma edição especial, apresentar uma encadernação de luxo [...] (BIBLIOTECA NACIONAL, 2006, grifo nosso)

Outra alternativa, seria colocá-las como Coleção de Reserva (CR), sem livre acesso ao usuário, onde a consulta é apenas local.

Com a automação do empréstimo, ampliação do guarda-volumes, a segurança nas catracas controlada pelos vigias e bolsistas, a instalação de câmaras de vídeo, vigilância constante por parte dos funcionários da BU as perdas diminuíram consideravelmente, mas não foram de todo eliminadas. Galbinski, Miranda e Flósculo (1993, p. 48) afirmam que a revista dos usuários na saída constitui-se uma das melhores formas disponíveis de proteção ao acervo. O controle de saída é considerado como fator que, se feito de forma adequada, diminui drasticamente os índices de perdas de publicações de uma biblioteca. (NILAND e KURTH ${ }^{3}$, 1976; RICHARDS JR ${ }^{4}, 1979$ apud NORONHA 1985, p.295)

Verifica-se a importância da realização de inventário rotativo, com uma periodicidade regular, de pelo menos dois anos. Com este procedimento, pode-se identificar melhor os problemas tais como: material danificado, rasurado, desaparecido, fora do lugar, ou de outra Biblioteca possibilitando intensificar as campanhas de conscientização, de preservação dos volumes, além de detectar mais rápida e facilmente as obras que precisam de substituição.

Considera-se importante, posteriormente, fazer uma análise do material desaparecido, em relação ao uso (consulta e empréstimo), pois estes itens constam nos relatórios anuais da Biblioteca. Com esta avaliação pode-se fazer investimento maior nas áreas mais prejudicadas.

\section{REFERÊNCIAS}

ASSOCIAÇÃO BRASILEIRA DE SUPERMERCADOS. Perdas nos supermercados chegam a 2,05\% do faturamento do setor. Disponível em:

http://www.abrasnet.com.br/noticias/noticias41.asp. Acesso em: 09 fev. 2007.

\footnotetext{
${ }^{3}$ NILAND P.; KURTH, W. H. Estimating lost volumes in a university library collection. College Research Library, v.37, n.2, p.128-136, 1976.

${ }^{4}$ RICHARDS JR., J. H. Missing inaction. Journal of Academic Librarianship, v.5 , n.5, p.266-269, 1979.
}

(c) Revista Digital de Biblioteconomia e Ciência da Informação,Campinas, v.6, n. 1, p. 84-100, jul/dez. 2008- ISSN: 1678-765X. 
BASINGER, Charlene. Collection inventory for a high school library. PNLA Quarterly, Boise, v.69, n.4, p.8-11, Summer 2005. Disponível em: http://vnweb.hwwilsonweb.com/hww/Journals/getIssues.jhtml?sid=HWW\%3ALIBFT\&i ssn=0030-8188\&un=aws57\&pw=cobz224946. Acesso em: 09 fev. 2007.

BIBLIOTECA NACIONAL (Brasil). Obras raras. 2006. Disponível em: http://www.bn.br/site/default.htm. Acesso em: 25 abr. 2007.

CARVALHO, Maria Carmen Romcy de. Estabelecimento de padrões para bibliotecas universitárias. Fortaleza: Edições UFC; Brasília: ABDF, 1981.

CHIAVENATO, Idalberto. Administração de materiais: uma abordagem introdutória. Rio de Janeiro: Elsevier, 2005.

CUNHA, Murilo Bastos da. Construindo o futuro: a biblioteca universitária brasileira em 2010. Ciência da Informação, Brasília, v. 29, n. 1, p. 71-89, jan./abr. 2000.

FUNDAÇÃO UNIVERSIDADE REGIONAL DE BLUMENAU. Biblioteca Universitária. Relatório de atividades, 2006. Blumenau , 2007.

FUNDAÇÃO UNIVERSIDADE REGIONAL DE BLUMENAU. Sistema integrado de Bibliotecas. Histórico. Disponível em: http://www.bc.furb.br/mambo/index.php?option=content\&task=view\&id=14\&Itemid=32. Acesso em: 20 mar. 2007.

GALBINSKI, José; MIRANDA, Antonio; FLÓSCULO, Frederico. Planejamento físico de bibliotecas universitárias. Brasilia, D.F : PROBIB, 1993.

MACIEL, Alba Costa. Instrumento para gerenciamento de bibliotecas. Niterói: EDUFF, 1995.

NORONHA, Daisy Pires, et al. Inventário de livros e periódicos em biblioteca acadêmica: estudo de caso. In: SEMINÁRIO NACIONAL DE BIBLIOTECAS 
UNIVERSITÁRIAS, 4., 1989, Campinas, SP. Anais.... Campinas : UNICAMP, 1985. p. 291-299.

PEÑASOLA, Fernando. Seleção e aquisição de livros: manual para bibliotecas. Washington: União Pan-Americana, 1961.

PIEROTTI, Maria de Lourdes Carvalho; NEILS, Valéria Rocha. Inventário rotativo: uma visão pragmática. Revista de Biblioteconomia de Brasília, Brasília, v. 13, n. 1, p.59-65, jan./jun. 1985.

\section{APÊNDICE A - VOLUMES NÃO LOCALIZADOS DA COLEÇÃO DE REFERÊNCIA (RF) POR ÁREA DO CONHECIMENTO}

\begin{tabular}{ccccc}
\hline Classificação & Total de volumes & $\begin{array}{c}\text { Volumes não } \\
\text { localizados }\end{array}$ & $\begin{array}{c}\mathbf{\%} \\
\text { Em 14 anos }\end{array}$ & $\begin{array}{c}\text { \% } \\
\text { anual }\end{array}$ \\
\hline 016 a 029 & 1.239 & 34 & 2,74 & 0,19 \\
030 a 090 & 1.238 & 31 & 2,50 & 0,17 \\
100 & 143 & 06 & 4,19 & 0,29 \\
200 & 97 & 01 & 1,03 & 0,07 \\
300 & 1.753 & 24 & 1,36 & 0,09 \\
400 & 1.066 & 41 & 3,84 & 0,27 \\
500 & 997 & 18 & 1,80 & 0,12 \\
600 & 1.854 & 26 & 1,40 & 0,10 \\
700 & 299 & 09 & 3,01 & 0,21 \\
800 & 116 & 07 & 6,03 & 0,43 \\
900 & 855 & 21 & 2,45 & 0,17 \\
Total & $\mathbf{9 . 6 5 7}$ & $\mathbf{2 1 8}$ & $\mathbf{2 , 2 5}$ & $\mathbf{0 , 1 6}$ \\
\hline
\end{tabular}

Fonte: Dados do Inventário 2007

APÊNDICE B - VOLUMES NÃo LOCALIZADOS DA COLEÇÃo GERAL (CG) POR ÁREA DO CONHECIMENTO 
ARTIGO

\begin{tabular}{|c|c|c|c|c|c|c|}
\hline Classificação & Assunto / Áreas & Total de volumes & $\begin{array}{l}\text { Volumes } \\
\text { localizados }\end{array}$ & não & $\begin{array}{l}\text { \% } \\
\text { Em } 14 \text { anos }\end{array}$ & $\begin{array}{l}\% \\
\text { anual }\end{array}$ \\
\hline 028.5 а 029 & & 2.410 & 202 & & 8,38 & 0,59 \\
\hline 050 a 090 & & 715 & 03 & & 0,41 & 0,02 \\
\hline 001 a 003 & & 1.730 & 23 & & 1,32 & 0,09 \\
\hline 004 a 019 & & 522 & 94 & & 18,0 & 1,28 \\
\hline 020 a 028 & & 369 & 09 & & 2,43 & 0,17 \\
\hline 100 a 149 & & 2.663 & 95 & & 3,56 & 0,25 \\
\hline 150 a 159 & & 6.624 & 94 & & 1,41 & 0,10 \\
\hline 160 a 169 & & 145 & - & & - & \\
\hline 170 a 179 & & 776 & $\overline{09}$ & & $\overline{1,15}$ & 0,08 \\
\hline 180 a 189 & & 295 & 07 & & 2,37 & 0,16 \\
\hline 190 a 199 & & 881 & 14 & & 1,58 & 0,11 \\
\hline 200 a 299 & & 2.834 & 57 & & 2,01 & 0,14 \\
\hline 300 a 309 & & 7.809 & 91 & & 1,16 & 0,08 \\
\hline 310 a 329 & & 4.158 & 84 & & 2,02 & 0,14 \\
\hline 330 a 339 & & 7.820 & 95 & & 1,21 & 0,08 \\
\hline 340 & & 2.511 & 39 & & 1,55 & 0,11 \\
\hline 341 & & 15.392 & 210 & & 1,36 & 0,09 \\
\hline 342 a 349 & & 7.033 & 98 & & 1,39 & 0,09 \\
\hline 350 & & 610 & 08 & & 1,31 & 0,09 \\
\hline 360 & & 2.636 & 33 & & 1,25 & 0,08 \\
\hline 370 & & 4.611 & 39 & & 0,84 & 0,06 \\
\hline 371 & & 2.703 & 20 & & 0,73 & 0,05 \\
\hline 372 & & 2.643 & 27 & & 1,02 & 0,07 \\
\hline 373 a 379 & & 2.565 & 15 & & 0,58 & 0,04 \\
\hline 380 & & 2.503 & 06 & & 0,23 & 0,01 \\
\hline 390 & & 834 & 19 & & 2,27 & 0,16 \\
\hline 400 & & 6.377 & 106 & & 1,66 & 0,11 \\
\hline 500 a 519 & & 3.232 & 106 & & 3,27 & 0,23 \\
\hline 520 & & 214 & 16 & & 7,44 & 0,53 \\
\hline 530 & & 1.154 & 32 & & 2,77 & 0,19 \\
\hline 540 & & 2.223 & 44 & & 1,97 & 0,14 \\
\hline 550 a 569 & & 711 & 14 & & 1,96 & 0,14 \\
\hline 570 & & 2.074 & 43 & & 2,07 & 0,14 \\
\hline 580 a 599 & & 1.475 & 38 & & 2,57 & 0,18 \\
\hline 600 a 610 & & 1.195 & 08 & & 0,66 & 0,04 \\
\hline 611 & & 711 & 06 & & 0,84 & 0,06 \\
\hline 612 & & 1.422 & 08 & & 0,56 & 0,04 \\
\hline 613 a 614 & & 1.248 & 16 & & 1,28 & 0,08 \\
\hline 615 & & 2.018 & 47 & & 2,32 & 0,16 \\
\hline 616 & & 5.009 & 46 & & 0,91 & 0,06 \\
\hline 617 & & 1.072 & 07 & & 0,65 & 0,04 \\
\hline 618 a 619 & & 1.486 & 03 & & 0,20 & 0,01 \\
\hline 620 a 629 & & 1.920 & 121 & & 6,30 & 0,45 \\
\hline 630 a 639 & & 1.101 & 44 & & 3,99 & 0,28 \\
\hline 640 a 649 & & 892 & 09 & & 1,00 & 0,07 \\
\hline 650 a 653 & & 536 & 08 & & 1,49 & 0,10 \\
\hline 657 a 657.9 & & 1965 & 25 & & 1,27 & 0,09 \\
\hline 658 & & 10.729 & 142 & & 1,32 & 0,09 \\
\hline 659 & & 565 & 03 & & 0,53 & 0,03 \\
\hline 660 a 689 & & 877 & 25 & & 2,85 & 0,20 \\
\hline 690 a 699 & & 409 & 32 & & 7,82 & 0,55 \\
\hline 700 & & 1.960 & 24 & & 1,22 & 0,08 \\
\hline 720 a 729 & & 1.073 & 31 & & 2,88 & 0,20 \\
\hline 730 a 779 & & 1.569 & 90 & & 5,73 & 0,40 \\
\hline 780 a 789 & & 1.143 & 27 & & 2,36 & 0,16 \\
\hline
\end{tabular}


ARTIGO

\begin{tabular}{lllll}
\hline $\mathbf{7 9 0}$ a 799 & 5.156 & 27 & 0,52 & 0,03 \\
$\mathbf{8 0 0}$ a 809 & 1.926 & 17 & 0,88 & 0,06 \\
$\mathbf{8 1 0}$ a 819 & 2.563 & 78 & 3,04 & 0,21 \\
$\mathbf{8 2 0}$ a 829 & 1.319 & 57 & 4,32 & 0,30 \\
$\mathbf{8 3 0}$ a 839 & 928 & 27 & 2,90 & 0,20 \\
$\mathbf{8 4 0}$ a 849 & 1.367 & 30 & 2,19 & 0,15 \\
$\mathbf{8 5 0}$ a 859 & 313 & 02 & 0,63 & 0,04 \\
$\mathbf{8 6 0}$ a 869 & 12.315 & 111 & 0,90 & 0,06 \\
$\mathbf{8 7 0}$ a 899 & 676 & 19 & 2,81 & 0,20 \\
$\mathbf{9 0 0}$ a 919 & 2.445 & 15 & 0,61 & 0,04 \\
$\mathbf{9 2 0}$ a 929 & 3.211 & 51 & 1,58 & 0,11 \\
$\mathbf{9 3 0}$ a 979 & 2.297 & 27 & 1,17 & 0,08 \\
$\mathbf{9 8 0}$ a 999 & 3.272 & 32 & 0,97 & 0,06 \\
Total & $\mathbf{1 7 7 . 0 3 7}$ & $\mathbf{3 . 0 0 5}$ & $\mathbf{1 , 6 9}$ & $\mathbf{0 , 1 2}$ \\
\hline
\end{tabular}

\section{Evanilde Maria Moser}

Chefe da Seção de Documentação e Automação da Biblioteca Universitária da Universidade Regional de Blumenau. Bibliotecária Especialista em Metodologia do Ensino e em Gestão Avançada em Recursos Humanos. emmoser@furb.br

\section{Jane Cristina Casas}

Chefe da Seção de Serviços ao Usuário da Biblioteca Universitária da Universidade Regional de Blumenau. Bibliotecária.jcasas@furb.br

\section{Maria Genoveva Lemos}

Diretora da Biblioteca Universitária da Universidade Regional de Blumenau. Bibliotecária Especialista em Metodologia do Ensino. lemos@furb.br

Recebido em: 29/06/2007

Aceito para publicação em: jan/2008 